Article

\title{
Potentiality of Self-Cloned Lactobacillus plantarum Taj-Apis362 for Enhancing GABA Production in Yogurt under Glucose Induction: Optimization and Its Cardiovascular Effect on Spontaneous Hypertensive Rats
}

\author{
Farah Salina Hussin ${ }^{1,2}$, Shyan Yea Chay ${ }^{1}$, Mohammad Zarei ${ }^{3}{ }^{\circledR}$, Anis Shobirin Meor Hussin ${ }^{1}$, \\ Wan Zunairah Wan Ibadullah ${ }^{1}$, Nurul Dhania Zaharuddin ${ }^{1}$, Hazrati Wazir ${ }^{1}$ and \\ Nazamid Saari ${ }^{1, *(1)}$ \\ 1 Department of Food Science, Faculty of Food Science and Technology, University Putra Malaysia, \\ Serdang Selangor 43400, Malaysia; farahsalina@unikl.edu.my (F.S.H.); shyan_yea@upm.edu.my (S.Y.C.); \\ shobirin@upm.edu.my (A.S.M.H.); wanzunairah@upm.edu.my (W.Z.W.I.); andee25@gmail.com (N.D.Z.); \\ hazratiwazir@gmail.com (H.W.) \\ 2 Section of Food Engineering Technology, Malaysian Institute of Chemical and Bio-Engineering Technology, \\ Universiti Kuala Lumpur, Alor Gajah, Melaka 78000, Malaysia \\ 3 Department of Food Science and Technology, School of Industrial Technology, Faculty of Applied Sciences, \\ Universiti Teknologi Mara, Shah Alam, Selangor 40450, Malaysia; zarei@uitm.edu.my \\ * Correspondence: nazamid@upm.edu.my; Tel.: +60-3-9769-8367
}

Received: 29 October 2020; Accepted: 18 November 2020; Published: 9 December 2020

check for updates

\begin{abstract}
The current study evaluated the $\gamma$-aminobutyric acid (GABA) producing ability from three novel strains of lactic acid bacteria (L. plantarum Taj-Apis362, assigned as UPMC90, UPMC91, and UPMC1065) co-cultured with starter culture in a yogurt. A combination of UPMC90 + UPMC91 with starter culture symbiotically revealed the most prominent GABA-producing effect. Response surface methodology revealed the optimized fermentation conditions at $39.0^{\circ} \mathrm{C}, 7.25 \mathrm{~h}$, and $11.5 \mathrm{mM}$ glutamate substrate concentration to produce GABA-rich yogurt $(29.96 \mathrm{mg} / 100 \mathrm{~g})$ with desirable $\mathrm{pH}(3.93)$ and water-holding capacity (63.06\%). At $2 \%$ glucose to replace pyridoxal-5-phosphate (PLP), a cofactor typically needed during GABA production, GABA content was further enhanced to $59.00 \mathrm{mg} / 100 \mathrm{~g}$. In vivo study using this sample revealed a blood pressure-lowering efficacy at $0.1 \mathrm{mg} / \mathrm{kg}$ GABA dosage (equivalent to $30 \mathrm{mg} / \mathrm{kg}$ GABA-rich yogurt) in spontaneously hypertensive rats. An improved method to produce GABA-rich yogurt has been established, involving shorter fermentation time and lower glutamate concentration than previous work, along with glucose induction that omits the use of costly PLP, fostering the potential of developing a GABA-rich functional dairy product through natural fermentation with desirable product quality and antihypertensive property.
\end{abstract}

Keywords: antihypertensive; fermentation; GABA; optimization; rat study; yogurt

\section{Introduction}

Hypertension is an underlying health complication that relates directly to the prevalence of cardiovascular diseases, including heart failure, coronary artery disease, stroke, atrial fibrillation, and peripheral vascular disease [1]. A continuous hypertension without proper treatment may lead to kidney failure, cognitive decline, and dementia [2]. According to WHO [3], 25\% of men and 20\% of women were diagnosed with hypertension in the year 2015, resulting in the occurrence of worldwide 
premature death. Along with the increasing health awareness and consumer demand towards food products that provide beyond basic nutrition (carbohydrate, protein, fat), food scientists are driven towards developing functional foods with additional health benefits.

One of the ingredients receiving such attention is gamma-aminobutyric acid (GABA), a non-proteinaceous amino acid that has been demonstrated to play a vital role in both the central and peripheral nervous system to consequently regulate blood pressure [4,5]. Numerous health benefits have been associated with GABA, including antihypertensive, antidiabetic, antistress, antidepression, and tranquilizing effects for patients suffering from neurological disorders [6]. GABA is naturally produced in various fermented foods, including sourdough [7], cheese [8], fermented milk [9], and fermented sausage [10], mainly as a result of lactic acid bacteria (LAB) metabolism. In LAB, L-glutamate substrate is actively converted into GABA via the irreversible $\alpha$-decarboxylation reaction, catalyzed by the presence of glutamic acid decarboxylase (GAD) enzyme in the microorganism. However, previous studies revealed that the effective production of GABA required a high concentration of glutamate (20-507 mM), the presence of costly pyridoxal-5-phosphate cofactor (PLP, 18-200 $\mu \mathrm{M})$, and a long fermentation time $(48-120 \mathrm{~h})[9,11,12]$. These major obstacles make up a tall order that deters the production of GABA-rich fermented foods under minimum usage of glutamate and PLP at a reduced incubation time.

While many studies reported the use of single-strain LAB to generate GABA, only few reported the production of GABA by co-culturing of different bacterial strains. For instance, Watanabe [13] and Kim et al. [14] demonstrated the ability of combined strains, i.e., S. thermophiles IFO13957 with L. bulgaricus IAM1120 and L. brevis GABA 100 with Bifidobacterium bifidum BGN4, respectively. In this study, self-cloned and expressed L. plantarum Taj-Apis362 recombinant cells, UPMC90 (intracellular) and UPMC91 (extracellular), previously engineered to have high GAD activity by Tajabadi et al. [15], were used to improve the GABA production in yoghurt and can be considered safe since modified organisms, by the self-cloning technique, are now not viewed as genetic modified organisms (GMOs) and are regarded as safe and suitable for food applications [16]. Following this, using yogurt as an example of a fermented food system, the current study performed response surface methodology (RSM) analysis to optimize the fermentation conditions (temperature, glutamate concentration, and incubation time) to maximize GABA production using the co-culturing technique, i.e., a combination of starter culture (S. thermophilus and L. delbrueckii ssp. bulgaricus) and high GABA-producing LAB strain (L. plantarum Taj-Apis362), prior to glucose induction to further enhance the GABA content. The final product with suitable $\mathrm{pH}$ and water-holding capacity was then administered to spontaneously hypertensive rats (SHR) for in vivo evaluation of blood pressure-lowering efficacy.

\section{Materials and Methods}

\subsection{Materials}

Non-fat skim milk powder (Sunlac ${ }^{\circledR}$ brand) and pasteurized fresh milk (Goodday ${ }^{\circledR}$ brand) were locally purchased. de Man, Rogosa and Sharpe (MRS) broth and MRS agar were obtained from HiMedia Laboratories Pvt. Ltd. (Mumbai, India). HPLC-grade ethanol (99.8\%) was purchased from Thermo Fisher Scientific (Waltham, MA, USA) while HPLC-grade acetonitrile was bought from Mallinckrodt Baker, Inc. (J.T. Baker ${ }^{\mathrm{TM}}$ brand, Phillipsburg, NJ, USA). GABA standard, glutamate substrate, triethylamine, and phenylisothiocyanate were purchased from Merck KGaA (Darmstadt, Germany). All other chemicals used were of analytical grade.

\subsection{Preparation of Starter Culture and GABA-Producing LAB Strains}

Commercial starter culture, consisting of $S$. thermophilus and L. delbrueckii ssp. bulgaricus was manufactured by YogurtBio (Lactina ${ }^{\circledR}$ brand, Sofia, Bulgaria). Two self-cloned L. plantarum Taj-Apis362 strains possessing high intracellular GAD activity (UPMC90) and high extracellular GAD activity (UPMC91) and a wild-type L. plantarum Taj-Apis362 (UPMC1065) were obtained from the culture 
collection of Institute of Bioscience, Universiti Putra Malaysia (Selangor, Malaysia). The wild-type L. plantarum Taj-Apis362 (UPMC1065) was previously isolated from the stomach of honeybee Apis dorsata, and used as a host for GAD gene overexpression to produce UPMC90 and UPMC91 strains. Due to the presence of extra GAD-producing gene as a result of genetic material exchange in self-cloned strains, the GAD activity increased by seven-fold compared to the wild-type host $[15,17]$. Samples were routinely stored in sterile MRS broth at $-80^{\circ} \mathrm{C}$ as stock culture. All procedures involving the use of L. plantarum Taj-Apis strains received approval from National Board of Biosafety, Ministry of Natural Resources and Environment, Malaysia (approval no. JBK [S]-602-1/2/207).

Prior to the production of a new batch of yogurt, starter culture and three LAB strains were freshly prepared before fermentation. Reconstituted skim milk was prepared according to the modified method of Sandoval-Castilla et al. [18]. Briefly, pasteurized fresh milk and skimmed milk powder were mixed to achieve $16 \%(w / v)$ non-fat total solid in the final volume, then subjected to thermal treatment at $80-85^{\circ} \mathrm{C}$ for $30 \mathrm{~min}$ [19], rapidly cooled to $4{ }^{\circ} \mathrm{C}$ in an iced bath, and stored at $4{ }^{\circ} \mathrm{C}$ before use. Starter culture was inoculated in the sterilized milk and incubated at $42^{\circ} \mathrm{C}$ for $6 \mathrm{~h}$ until reaching pH 4.5-4.6. On the other hand, LAB strains were streaked on three different MRS fresh agar plates for single colony isolation, then individually transferred to $10 \mathrm{~mL}$ of MRS broth to allow rapid cell growth, incubated at $37^{\circ} \mathrm{C}$ for $18 \mathrm{~h}$, and finally sub-cultured at $37^{\circ} \mathrm{C}$ for $22-24 \mathrm{~h}$ in $10 \mathrm{~mL}$ of sterile reconstituted skimmed milk. At the end of the incubation, a thick semi-solid layer of bacterial mass (curd) was formed and used for yogurt production, as detailed in Section 2.3.

\subsection{Yogurt Fermentation}

On the day of fermentation, bacterial curd (starter culture and LAB, having a viable cell count of $>10^{6} \mathrm{CFU} / \mathrm{g}$ ) were mixed at a ratio of 2:1 (weight of starter culture to weight of LAB) into sterilized reconstituted skim milk to produce 5 different samples: control (denoted as $S$, contained only starter culture), S+UPMC90, S+UPMC91, S+UPMC90+UPMC91, and S+UPMC1065. Glutamate substrate was added at $5 \mathrm{mM}$ and fermentation was allowed at $36{ }^{\circ} \mathrm{C}$ for $10 \mathrm{~h}$ [15]. For glucose-induced samples, $1-4 \%$ glucose $(w / v)$ was added to four different samples prior to fermentation at the optimized conditions obtained. Glucose was selected based on a preliminary study that evaluated the effect of different simple sugars and prebiotics to enhance GABA in a yogurt system (data not shown). Samples were taken at hourly intervals, rapidly cooled in an iced bath to stop fermentation, and stored in a freezer at $-20^{\circ} \mathrm{C}$ prior to further analysis.

\subsection{Experimental Design for RSM Study}

Optimization of fermentation conditions was performed using a central composite design to maximize GABA yield. Three independent variables were selected, namely temperature $\left(35-43^{\circ} \mathrm{C}\right)$, glutamate concentration (2-30 mM), and incubation time (4-10 h). The response variables were GABA content, $\mathrm{pH}$, and water-holding capacity (WHC). A total of 20 runs, consisting of different temperatures, glutamate concentrations, and incubation times, were performed in randomized order (Table 1) and in triplicate to minimize the effect of unexplained variability in the actual responses due to extraneous factors. At the end of fermentation, samples were either directly measured for $\mathrm{pH}$ or rapidly cooled in an iced bath, then stored at $-20^{\circ} \mathrm{C}$ for GABA and glutamate determination or stored at $4{ }^{\circ} \mathrm{C}$ for WHC analysis. 
Table 1. Central composite design with actual experimental and predicted response values for yogurt fermented by S+UPMC90+UPMC91 LAB strains.

\begin{tabular}{|c|c|c|c|c|c|c|c|c|c|}
\hline \multirow[b]{2}{*}{ Run } & \multicolumn{3}{|c|}{ Factor } & \multicolumn{6}{|c|}{ Response } \\
\hline & $\begin{array}{r}X_{1}, \\
\left({ }^{\circ} \mathrm{C}\right)\end{array}$ & $\begin{array}{c}X_{2} \\
(\mathrm{mM})\end{array}$ & $\begin{array}{c}X_{3}, \\
\text { (hour) }\end{array}$ & $\begin{array}{c}\text { Actual } \\
\text { GABA } \\
(\mathrm{mg} / 100 \mathrm{~g})\end{array}$ & $\begin{array}{c}\text { Predicted } \\
\text { GABA } \\
(\mathrm{mg} / 100 \mathrm{~g})\end{array}$ & $\begin{array}{c}\text { Actual } \\
\text { pH }\end{array}$ & $\begin{array}{c}\text { Predicted } \\
\mathrm{pH}\end{array}$ & $\begin{array}{c}\text { Actual } \\
\text { WHC } \\
(\%)\end{array}$ & $\begin{array}{c}\text { Predicted } \\
\text { WHC } \\
(\%)\end{array}$ \\
\hline 1 & 39 & 30 & 7 & 29.03 & 26.13 & 3.81 & 3.84 & 63.87 & 63.24 \\
\hline 2 & 39 & 16 & 4 & 25.03 & 24.65 & 4.55 & 4.59 & 61.41 & 61.57 \\
\hline 3 & 39 & 16 & 7 & 31.25 & 31.36 & 3.96 & 3.95 & 63.47 & 64.49 \\
\hline 4 & 39 & 16 & 7 & 30.98 & 31.36 & 3.92 & 3.95 & 64.91 & 64.49 \\
\hline 5 & 35 & 30 & 4 & 0.00 & 5.10 & 4.93 & 4.92 & 50.25 & 50.64 \\
\hline 6 & 39 & 16 & 7 & 31.12 & 31.36 & 3.95 & 3.95 & 63.82 & 64.49 \\
\hline 7 & 39 & 16 & 7 & 32.53 & 31.36 & 3.97 & 3.95 & 62.37 & 64.49 \\
\hline 8 & 35 & 30 & 10 & 27.28 & 24.43 & 3.99 & 4.01 & 57.54 & 59.38 \\
\hline 9 & 35 & 2 & 4 & 10.00 & 7.87 & 4.98 & 4.97 & 47.69 & 48.32 \\
\hline 10 & 35 & 2 & 10 & 24.32 & 27.20 & 3.94 & 3.93 & 57.17 & 57.06 \\
\hline 11 & 39 & 16 & 10 & 32.57 & 38.07 & 3.85 & 3.84 & 68.67 & 67.42 \\
\hline 12 & 43 & 2 & 4 & 12.85 & 14.26 & 4.47 & 4.47 & 48.43 & 49.52 \\
\hline 13 & 43 & 30 & 10 & 28.41 & 29.10 & 3.98 & 3.96 & 54.08 & 54.82 \\
\hline 14 & 39 & 16 & 7 & 29.31 & 31.36 & 3.96 & 3.95 & 65.26 & 64.49 \\
\hline 15 & 43 & 2 & 10 & 24.02 & 21.76 & 3.87 & 3.89 & 53.78 & 52.49 \\
\hline 16 & 35 & 16 & 7 & 25.52 & 22.52 & 4.30 & 4.30 & 59.02 & 56.27 \\
\hline 17 & 39 & 16 & 7 & 35.32 & 31.36 & 3.98 & 3.95 & 65.09 & 64.49 \\
\hline 18 & 43 & 16 & 7 & 27.84 & 28.05 & 4.00 & 4.03 & 52.78 & 54.59 \\
\hline 19 & 43 & 30 & 4 & 21.63 & 21.59 & 4.44 & 4.42 & 54.20 & 51.85 \\
\hline 20 & 39 & 2 & 7 & 23.74 & 23.85 & 3.83 & 3.83 & 61.23 & 60.91 \\
\hline
\end{tabular}

$X_{1}$ : temperature; $X_{2}$ : glutamate concentration; $X_{3}$ : time.

Regression analysis and analysis of variance (ANOVA) were performed to determine the regression coefficients and statistical significance of the model terms. Model competency was monitored using model $p$-value, lack-of-fit $p$-value, and coefficient of determination $\left(R^{2}\right)$, of which statistically significant terms with $p$-values $<0.05$ were included in the reduced model. For linear terms, either significant $(p<0.05)$ or non-significant $(p>0.05)$, were all retained in the final reduced model. Progressively, three-dimensional (3-D) response surface plots were employed to show the relationship between responses and independent variables. All experimental design and data analysis was performed using Design-Expert ${ }^{\circledR}$ software (version 7, Stat-Ease Inc., Minneapolis, MN, USA).

\subsection{Determination of $G A B A$ Content}

GABA content was determined following the method previously described by Tajabadi et al. [15] using an HPLC system (Shimadzu LC 20AT, Shimadzu Corporation, Kyoto, Japan) equipped with an oven (model CT0-10ASVP), pump system, and PDA detector (model SPD-M20A). The separation column (endcapped Chromolith ${ }^{\circledR}$ RP-18, $100 \mathrm{~mm}$ length $\times 4.6 \mathrm{~mm}$ internal diameter) was supplied by Merck KGaA (Darmstadt, Germany). Briefly, $1.0 \mathrm{~g}$ of yogurt sample was centrifuged at $10,000 \times g$ at $4{ }^{\circ} \mathrm{C}$ for $15 \mathrm{~min}$ and $10 \mu \mathrm{L}$ of the supernatant were collected in small durham tube for evaporation under vacuum for $40 \mathrm{~min}$ (known as derivatization). The dried supernatant was then dissolved in $20 \mu \mathrm{L}$ of ethanol/water/trimethylamine/phenylisothiocyanate solution (prior mixed at a ratio of 2:2:1) and immediately evaporated under vacuum for $40 \mathrm{~min}$. Next, $30 \mu \mathrm{L}$ of ethanol/water/triethylamine/phenylisothiocyanate solution (prior mixed at 7:1:1:1) were added into the sample and left for $20 \mathrm{~min}$ at room temperature to allow phenylisothiocyanate-GABA formation. The sample was vacuumed again for $40 \mathrm{~min}$ to remove excess solvent, then diluted and subjected to HPLC analysis. Mobile phase A ( $\mathrm{pH} 5.8$, adjusted using $0.1 \mathrm{M} \mathrm{NaOH}$ ) consisted of $8.205 \mathrm{~g}$ of sodium acetate, $0.5 \mathrm{~mL}$ trimethylamine, and $0.7 \mathrm{~mL}$ acetic acid in $1 \mathrm{~L}$ of deionized water while mobile phase $\mathrm{B}$ consisted of $1 \mathrm{~L}$ of acetonitrile and deionized water mixed at a ratio of 3:2. Both mobile phases were 
filtered through a $0.45-\mu \mathrm{m}$ membrane filter. Sample was injected at $5 \mu \mathrm{L}$ and eluted at a flow rate of $0.6 \mathrm{~mL} / \mathrm{min}$ using isocratic elution of $80 \%$ mobile phase $\mathrm{A}+20 \%$ mobile phase B. Compound was identified at $\lambda=254 \mathrm{~nm}$ using a diode array detector. GABA content was calculated by comparing the sample peak area with that of GABA standard.

\subsection{Determination of $\mathrm{pH}$}

All $\mathrm{pH}$ measurements were performed using a bench-top $\mathrm{pH}$ meter (model S20 SevenEasy ${ }^{\mathrm{TM}}$, Mettler-Toledo $\mathrm{GmbH}$, Columbus, OH, USA).

\subsection{Determination of Water-Holding Capacity (WHC)}

WHC was determined according to the modified procedure as described by Abdelmoneim et al. [20]. A sample of $10.0 \mathrm{~g}$ of yogurt $\left(W_{1}\right)$ was centrifuged at $5000 \times \mathrm{g}$ for $10 \mathrm{~min}$ at $4{ }^{\circ} \mathrm{C}$. The supernatant was collected and weighed $\left(W_{2}\right)$. WHC $(\%)$ was calculated as follows:

$$
\mathrm{WHC}=\frac{W_{1}-W_{2}}{W_{1}} \times 100 \%
$$

\subsection{Animal Study: Blood Pressure-Lowering Efficacy in SHR}

Thirty-six male spontaneously hypertensive rats (aged 10 weeks old) were purchased from Animal Experimental Unit, Faculty of Medicine, University of Malaya (Kuala Lumpur, Malaysia) and acclimatized to laboratory conditions for 7 days prior to the experiment. All rats were housed in three per individually ventilated cage, at a room temperature of $22-24{ }^{\circ} \mathrm{C}$, relative humidity of $50-60 \%$, and maintained under an automated 12-h light/dark cycle. A standard fortified pellet diet (Altromin brand) and distilled water were available ad libitum.

The rats were randomly divided into 6 groups: positive control (captopril, $50 \mathrm{mg} / \mathrm{kg}$, a pharmaceutical antihypertensive agent), negative control (distilled water), control yogurt (containing only starter culture, $30 \mathrm{mg} / \mathrm{kg}$ ), and three doses of yogurt $(30,150,300 \mathrm{mg} / \mathrm{kg}$ ) corresponding to $0.1,0.5$, and $1.0 \mathrm{mg} / \mathrm{kg}$ GABA, respectively. The exact amount of yogurt fed to each rat was calculated based on their individual body weights. Weighed freeze-dried yogurt samples were dissolved in distilled water and topped up to $1.0 \mathrm{~mL}$ prior to administration using the oral gavage technique. Systolic blood pressure was measured after warming the animal at $37^{\circ} \mathrm{C}$ for $10 \mathrm{~min}$ using a CODA non-invasive blood pressure system (Kent Scientific, CT, USA) by applying the tail-cuff method. Measurements were performed at 0 (before administration), 2, 4, 6, 8, and $24 \mathrm{~h}$ after administration. Rats were kept in a peaceful and calm condition prior to measurement. All procedures were performed according to the approval from Institutional Animal Care and Use Committee, Universiti Putra Malaysia (ethic no. UPM/IACUC/AUP-R072/2018).

\subsection{Statistical Analysis}

Analysis of variance (ANOVA) followed by Duncan's test were performed to detect means at significant difference $(p<0.05)$ in all analyses. Student's $t$-test was performed in RSM study to compare actual and predicted responses during model validation. Results were analyzed using Minitab ${ }^{\circledR}$ statistical software version 16 (Minitab Inc., State College, PA, USA). All values were reported as mean \pm standard deviation from at least triplicate determinations.

\section{Results and Discussion}

\subsection{GABA-Producing Ability of Different LAB Strains}

Three different strains of L. plantarum Taj-Apis362 (two self-cloned UPMC90 and UPMC91, and one wild-type UPMC1065) were co-cultured with starter culture (a mixture of S. thermophilus and L. delbrueckii ssp. bulgaricus) to produce yogurt and evaluated the GABA-producing potential of 
these selected strains. Five yogurt samples were produced, namely control containing only the starter culture (S), S+UPMC90, S+UPMC91, S+UPMC90+UPMC91, and S+UPMC1065. Their respective GABA content and $\mathrm{pH}$ profiles, monitored over $10 \mathrm{~h}$ of fermentation, are shown in Figure 1 . It is interesting to note that a combination of two self-cloned LAB strains (S+UPMC90+UPMC91) produced the highest GABA content $(25.36 \mathrm{mg} / 100 \mathrm{~g})$, followed by S+UPMC91 $(21.05 \mathrm{mg} / 100 \mathrm{~g}), \mathrm{S}+$ UPMC90 $(18.23 \mathrm{mg} / 100 \mathrm{~g})$, and S+UPMC1065 (17.76 mg/100 g) after $10 \mathrm{~h}$ of fermentation. In contrast, the control produced the lowest GABA content of $8.29 \mathrm{mg} / 100 \mathrm{~g}$, which was significantly lower than all samples co-cultured with LAB strains. These findings revealed the different degree of GABA enhancement by all selected L. plantarum Taj-Apis362 strains in yogurt, indicating the potential of developing GABA-rich food through natural fermentation.

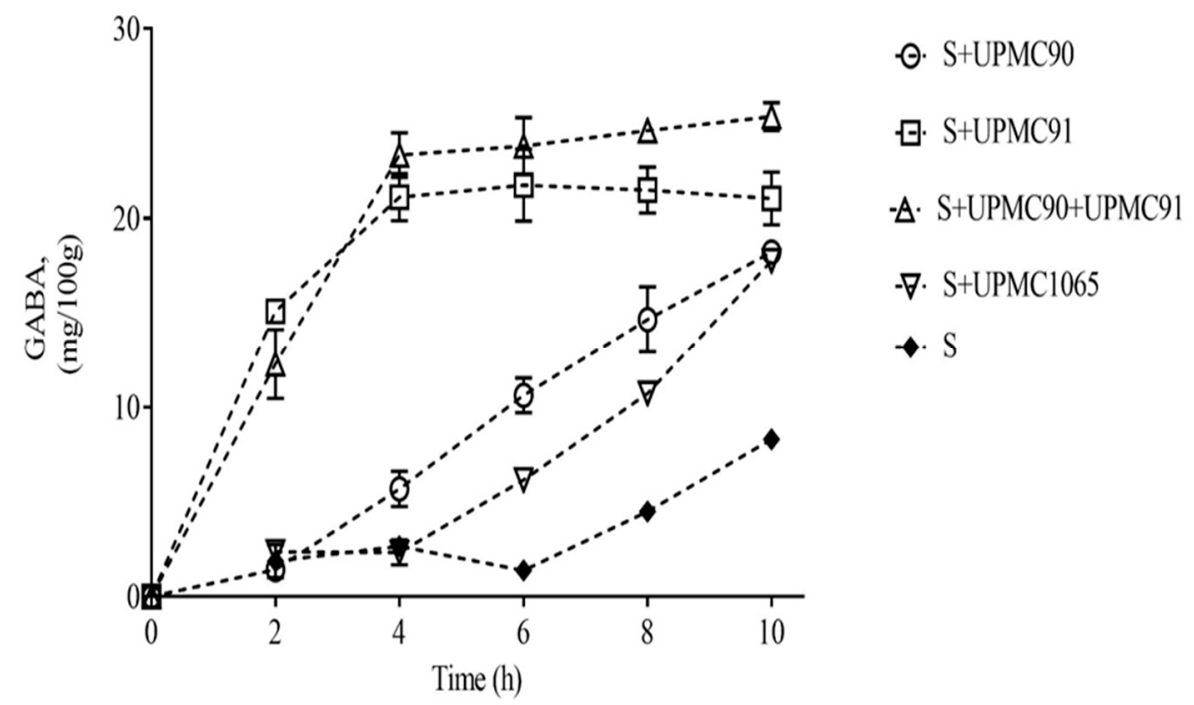

Figure 1. The changes in GABA content of five yogurt samples fermented at $5 \mathrm{mM}$ glutamate and $36^{\circ} \mathrm{C}$ for $10 \mathrm{~h}$. S denotes starter culture containing only S. thermophilus and L. delbrueckii ssp. Bulgaricus.

Meanwhile, all samples, with or without the presence of $\mathrm{LAB}$, showed a concomitant reduction in $\mathrm{pH}$, from $\mathrm{pH} 6.0$ to 4.0 , over $10 \mathrm{~h}$ of fermentation. This reduction is mostly contributed by the active metabolism of starter cultures, whereby $S$. thermophilus primarily dominates the early phase of fermentation at $\mathrm{pH}$ 6.5-5.5 and subsequently stimulates the growth of L. delbrueckii ssp. bulgaricus to reach a lower $\mathrm{pH}$ of 4.5-4.0. This acidic condition leads to the formation of gel particles in the yogurt, giving rise to a thick and curd-like consistency in the product [21,22]. The presence of LAB did not contribute significantly towards $\mathrm{pH}$ reduction in the samples. This is due to the fact that, even though lactic acid is constantly produced, the bacteria utilizes protons to support GAD enzyme activity for decarboxylation of glutamate into GABA, counteracting the effect of lactic acid and resulting in an unchanged $\mathrm{pH}[23,24]$. For instance, S+UPMC90+UPMC91 produced the highest GABA content with $\mathrm{pH}$ similar to control (without the addition of $\mathrm{LAB}$ ), suggesting that co-culturing LAB with high intracellular (UPMC90) and extracellular (UPMC91) GAD activity with starter culture significantly intensifies GABA production without jeopardizing the physicochemical quality. The increased conversion from glutamate to GABA during co-culturing pleasantly reveals the symbiotic relationship between starter culture and LAB to stimulate higher metabolic activity among the microorganisms [21]. This finding is in line with previous studies performed by Xiao et al. [25] and Hugenschmidt et al. [26], who used Levilactobacillus brevis strain NPS-QW 145 co-cultured with Streptococcus thermophilus to increase GABA production in milk and Lactobacillus plantarum SM39 co-cultured with Propionibacterium freudenreichii DF13 to produce high folate and vitamin B12, respectively. Taking this into account, S+UPMC90+UPMC91 was selected for further optimization study. 


\subsection{Optimization of Fermentation Parameters}

Response surface methodology (RSM) was applied to optimize the fermentation parameters to produce GABA-rich yogurt. Three independent variables (temperature, glutamate substrate concentration, and incubation time) were chosen based on their dominant role to enhance GABA in GABA-producing microorganisms [27]. Three responses were monitored, i.e., GABA content, $\mathrm{pH}$, and water-holding capacity (WHC). In bovine milk, $80 \%$ of protein is made up of casein micelles, of which their stability is highly dependent on the net negative charge and steric repulsion of $k$-casein at natural milk $\mathrm{pH}$ [28]. During fermentation, the produced hydrogen ion $\left(\mathrm{H}^{+}\right)$neutralizes the negative charges, reducing the electrostatic repulsion between casein molecules to promote the formation of protein clusters and chains into a three-dimensional network, effectively entrapping water molecules to improve the WHC. Additionally, when $\mathrm{pH}$ reduces, the stabilizing layer surrounding casein molecules tends to collapse and weaken, bringing the molecules to a closer proximity, forming dense clusters and pact structures to facilitate gelling [29]. Thus, $\mathrm{pH}$ and WHC were selected as responses of interest in the current study due to their strong correlation with the gel-forming ability, which subsequently affects the yogurt quality.

The fermentation conditions (factors) and their corresponding actual and predicted GABA, $\mathrm{pH}$, and WHC (responses) are detailed in Table 1. Statistical parameters, including $p$-value, F-value, lack-of-fit, and $R$-squared $\left(R^{2}\right)$, from multiple regression analysis were used complementarily to help identify the best-fitting model, of which the polynomial quadratic model was found to be the most suitable to describe the effect of temperature $\left(X_{1}\right)$, glutamate concentration $\left(X_{2}\right)$, and incubation time $\left(X_{3}\right)$ on the GABA, $\mathrm{pH}$, and WHC of yogurt. From Table 2 , the analysis of variance (ANOVA) revealed model $p$-value $<0.0001$ and $R^{2}>90 \%$ for all three responses, with $F$-values of $17.75,431.32$, and 45.65 , for GABA, pH, and WHC, respectively. According to Karthikeyan et al. [30], a combination of a large F-value and small $p$-value suggested a significant effect on the respective response in any model. In addition, the $p$-values for lack-of-fit were insignificant $(p>0.05)$ for all measured responses. Adequate precision (measures the signal-to-noise ratio) of 16.24-64.80 was obtained in the current study and a ratio greater than 4 is considered as desirable to indicate adequate signal [31]. These observations suggest that the final reduced quadratic model sufficiently represented the obtained data and demonstrates high significance to predict any response accurately under any combination of fermentation parameters.

Table 2. Analysis of variance (ANOVA) for the full quadratic model of GABA content, $\mathrm{pH}$, and water-holding capacity obtained during optimization.

\begin{tabular}{ccccccc}
\hline & \multicolumn{2}{c}{ GABA } & \multicolumn{2}{c}{ pH } & \multicolumn{2}{c}{ WHC } \\
\cline { 2 - 7 } & F-Value & $p$-Value & $F$-Value & $p$-Value & $F$-Value & $p$-Value \\
\hline Model & 17.75 & $<0.0001$ & 431.32 & $<0.0001$ & 45.65 & $<0.0001$ \\
$X_{1}$ & 7.41 & 0.0185 & 275.24 & $<0.0001$ & 2.78 & 0.1192 \\
$X_{2}$ & 1.26 & 0.2832 & 0.52 & 0.4858 & 5.37 & 0.0375 \\
$X_{3}$ & 43.68 & $<0.0001$ & 2021.62 & $<0.0001$ & 33.75 & $<0.0001$ \\
$X_{1}{ }^{2}$ & 11.47 & 0.0054 & 189.20 & $<0.0001$ & 103.86 & $<0.0001$ \\
$X_{2}{ }^{2}$ & 12.60 & 0.0040 & 49.70 & $<0.0001$ & 7.32 & 0.0180 \\
$X_{3}{ }^{2}$ & & & 285.86 & $<0.0001$ & & \\
$X_{1} X_{2}$ & 4.95 & 0.0459 & & & & \\
$X_{1} X_{3}$ & 6.78 & 0.0230 & 152.91 & $<0.0001$ & 6.56 & 0.0237 \\
$X_{2} X_{3}$ & & & 10.41 & 0.0081 & & \\
Lack of fit & 3.59 & 0.0891 & 2.14 & 0.2107 & 2.58 & 0.1558 \\
$R_{2}$ & $91.19 \%$ & & $99.68 \%$ & & $95.47 \%$ & \\
$R_{2}$ adjusted & $86.06 \%$ & & $99.45 \%$ & & $93.38 \%$ & \\
\hline
\end{tabular}

Note: $X_{1}=$ Temperature $\left({ }^{\circ} \mathrm{C}\right), X_{2}=$ Glutamate concentration $(\mathrm{mM}), X_{3}=$ Time (hour). 
From Table 2, linear terms of temperature $\left(X_{1}\right)$ and incubation time $\left(X_{3}\right)$ had significant effects on GABA and $\mathrm{pH}(p<0.05)$, while glutamate concentration $\left(X_{2}\right)$ had no effect on these responses $(p>0.05)$. WHC were significantly affected by $X_{2}$ and $X_{3}$ but not by $X_{1}$. On the other hand, the quadratic effect of temperature $\left(X_{1}^{2}\right)$ and glutamate concentration $\left(X_{2}^{2}\right)$ was seen on all responses $(p<0.05)$, but that of time $\left(X_{3}{ }^{2}\right)$ was only observed on $\mathrm{pH}$. As for interactive effects, $X_{1} X_{3}$ produced significant effect on all responses $(p<0.05)$, while $X_{1} X_{2}$ and $X_{2} X_{3}$ exerted a significant effect on GABA and $\mathrm{pH}$, respectively. The final reduced model, containing only the significant terms, for GABA, $\mathrm{pH}$, and WHC, is expressed as follows.

$$
\begin{gathered}
Y_{1}=31.36+2.76 X_{1}+1.14 X_{2}+6.71 X_{3}-6.08 X_{1}^{2}-6.37 X_{2}^{2}+2.53 X_{1} X_{2}-2.96 X_{1} X_{3}, \\
Y_{2}=3.95-0.14 X_{1}+0.006 X_{2}-0.37 X_{3}+0.22 X_{1}^{2}-0.11 X_{2}^{2}+0.27 X_{3}^{2}+0.11 X_{1} X_{3}+0.03 X_{2} X_{3} \\
Y_{3}=64.49+0.84 X_{1}+1.16 X_{2}+2.93 X_{3}-9.07 X_{1}^{2}-2.42 X_{2}^{2}-1.44 X_{1} X_{3},
\end{gathered}
$$

where responses are represented by $Y_{1}=\mathrm{GABA}(\mathrm{mg} / 100 \mathrm{~g}), Y_{2}=\mathrm{pH}$ (unitless), and $Y_{3}=\mathrm{WHC}$ $(\%)$; and factors are represented by $X_{1}=$ temperature $\left({ }^{\circ} \mathrm{C}\right), X_{2}=$ glutamate concentration $(\mathrm{mM})$, and $X_{3}=$ incubation time (hour).

All significant interactions on GABA, $\mathrm{pH}$, and $\mathrm{WHC}$, from different fermentation factor combinations, are illustrated as three-dimensional response surface plots in Figure 2. At a fixed incubation time of $7 \mathrm{~h}$, the temperature-glutamate interaction effect positively enhanced GABA production, reaching a maximum at $39^{\circ} \mathrm{C}$ and $16 \mathrm{mM}$ glutamate, followed by a reduction when temperature and glutamate further increased to $43^{\circ} \mathrm{C}$ and $30 \mathrm{mM}$, respectively (Figure 2a). These results implied that the interaction from temperature and glutamate played a critical role in enhancing GABA production in LAB strains, in line with that previously reported by Li et al. [32], who showed that temperature and glutamate significantly increased GABA production in Lactobacillus species. However, excessively high temperature and glutamate were unfavorable to an enhancement of GABA production, due to the restricted cell growth under extreme conditions [33,34]. Similarly, at a fixed glutamate concentration of $16 \mathrm{mM}$, the temperature-time interaction enhanced GABA production, which then reduced when the parameters further increased to $43^{\circ} \mathrm{C}$ and $10 \mathrm{~h}$ (Figure 2b).

The contour plot in Figure 2c shows the temperature-time interaction effect on $\mathrm{pH}$. At a fixed glutamate concentration of $16 \mathrm{mM}, \mathrm{pH}$ was inversely correlated to the temperature-time interaction, i.e., as temperature and time increased, the $\mathrm{pH}$ was lowered. This is due to the conversion of milk sugar (lactose) into lactic acid, as a result of bacterial metabolism during fermentation in the yogurt [35]. A similar inverse correlation was observed for the glutamate-time interaction effect on $\mathrm{pH}$ (Figure 2d), which recorded a reduced $\mathrm{pH}$ when glutamate and time increased. This may be attributed to the utilization of glutamate as a nitrogen source by bacterial cells to sustain growth, which produced lactic acid and lowered the $\mathrm{pH}$ as fermentation continued [36].

The contour plot in Figure 2e shows the temperature-time interaction effect on WHC, whereby WHC reached a maximum at $39^{\circ} \mathrm{C}$ and $7 \mathrm{~h}$ but reduced gradually when the parameters further increased to $43^{\circ} \mathrm{C}$ and $10 \mathrm{~h}$. Kristo et al. [37] and Lazaridou et al. [38] observed that, at low fermentation temperatures, the hydrophobic interaction between casein micelles is weak, allowing protein molecules to gather in close proximity and form large clusters, building an extensive and strong protein network to produce a firm and dense gel structure that effectively immobilizes free water molecules in the gel matrix [39], thus improving the WHC. On the contrary, when the temperature continues to increase, hydrophobic interaction dominates, and casein micelles re further distanced apart, weakening the gel's ability to entrap water molecules, and thus reducing the WHC. All selected parameters exerted significant linear, quadratic, and interaction effects on GABA, $\mathrm{pH}$, and WHC, indicating that the fermentation parameters should be carefully manipulated to obtain GABA-rich yogurt with desirable product qualities. 


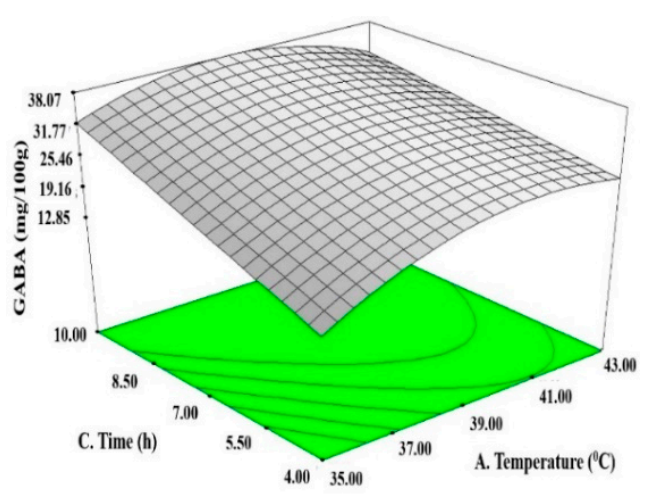

(a)

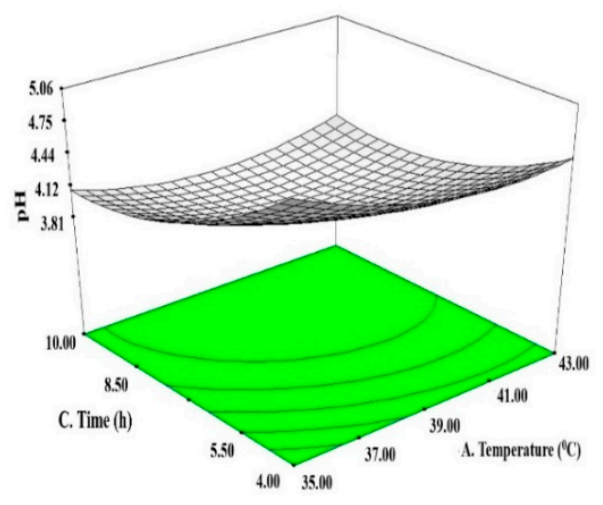

(c)

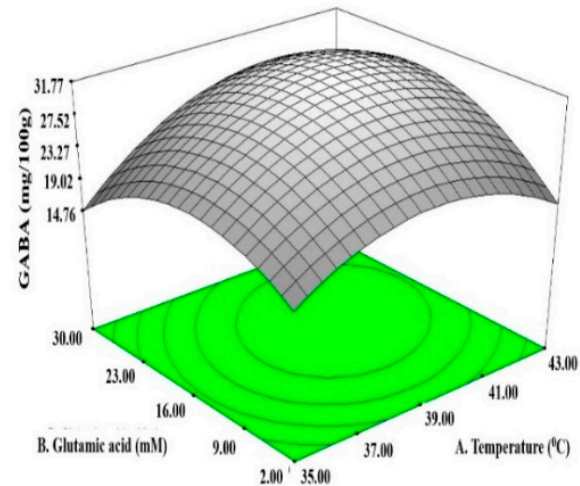

(b)

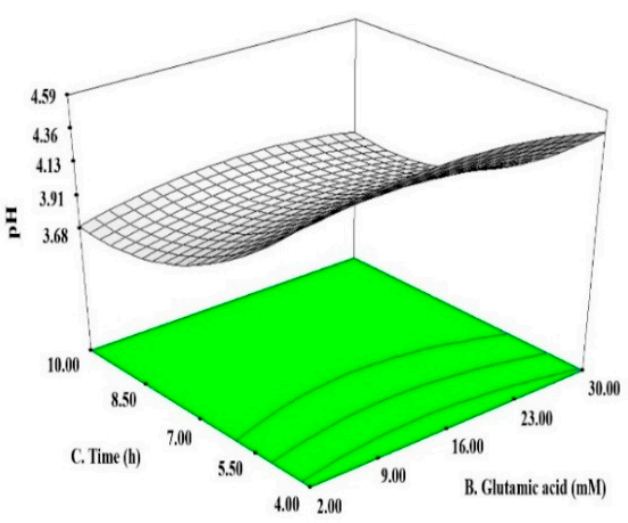

(d)

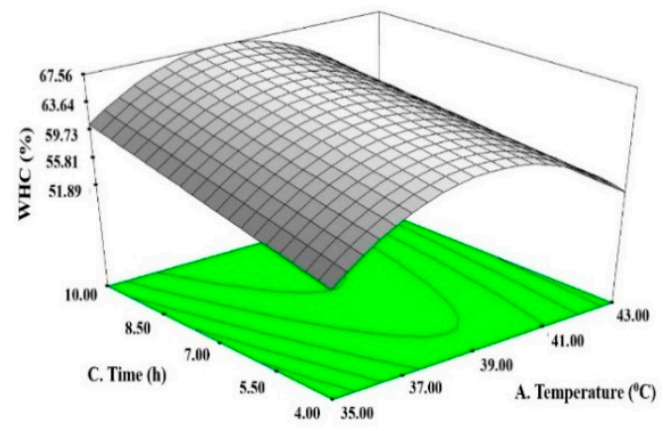

(e)

Figure 2. Three-dimensional response surface plots showing significant interaction between different factor combinations during fermentation; (a) Effect of temperature and glutamate on GABA, (b) Effect of temperature and time on GABA, (c) Effect of temperature and time on $\mathrm{pH}$, (d) Effect of glutamate and time on $\mathrm{pH}$; and (e) Effect of temperature and time on water-holding capacity.

\subsection{RSM Model Validation}

Model validation was performed following the predicted fermentation conditions to verify the accuracy and best-fit character of the selected model. The optimized conditions were predicted as follows: fermentation temperature $=39.0^{\circ} \mathrm{C}$, glutamate concentration $=11.5 \mathrm{mM}$, and incubation time $=7.25 \mathrm{~h}$ to yield GABA $=30.90 \mathrm{mg} / 100 \mathrm{~g}, \mathrm{pH}=3.90$, and $\mathrm{WHC}=64.11 \%$ theoretically. The actual experimental values obtained under these conditions were GABA $=29.96 \mathrm{mg} / 100 \mathrm{~g}, \mathrm{pH}=3.93$, and $\mathrm{WHC}=63.06 \%$, respectively. According to Duttschaever et al. [40], normal pH values ranging from 3.27-4.53 have been reported for commercial yogurts and yogurts with WHC of 43.22-68.78\% were 
found acceptable by experienced panelists [41]. The optimized $\mathrm{pH}$ and WHC obtained for GABA-rich yogurt were within the acceptable range. Student's $t$-test revealed $p>0.05$ for all comparisons, indicating no significant difference between actual and predicted values. This confirms the model's significance and adequacy to predict the optimum fermentation parameters to produce GABA-rich yogurt with desirable $\mathrm{pH}$ and WHC.

\subsection{Glucose Induction for Enhancing GABA Production}

Upon establishing the optimum fermentation conditions to produce GABA-rich yogurt, the effect of glucose to further enhance GABA production was investigated, whereby four levels of glucose $(1-4 \%, w / v)$ were added into the yogurt prior to fermentation under optimized conditions. Figure 3 depicts that $2 \%$ glucose significantly induced GABA enhancement, in agreement with a previous study by Li et al. [42], who reported a glucose concentration of $2.5 \%$ as the best carbon level to enhance GABA production by L. brevis NCL912 in culture broth. In the present study, $2 \%$ glucose induced GABA production to $59.00 \mathrm{mg} / 100 \mathrm{~g}$, a two-fold increment compared to that without glucose $(29.96 \mathrm{mg} / 100 \mathrm{~g})$. This finding is prominent and uplifting, as it strengthens the omission of expensive cofactor (pyridoxal-5-phosphate) from the fermentation medium and allows the minimal usage of glutamate substrate that would otherwise exert unfavorable savory/umami taste if present at a high concentration. In fact, the current work delightfully demonstrates the lowest glutamate concentration $(11.5 \mathrm{mM})$ compared to previous work, which required up to 20-507 mM glutamate for GABA production [9,11,12]. In terms of incubation time, Chen et al. [43] reported a GABA yield of $7.30 \mathrm{~g} / \mathrm{L}$ in fermented milk only after $72 \mathrm{~h}$ of incubation with Streptococcus salivarius subsp. thermophiles fmb5 at $1.2 \%$ glutamate and $37^{\circ} \mathrm{C}$ while Linares et al. [6] observed a GABA content of $2.20 \mathrm{mg} / \mathrm{mL}$ in yogurt cultured with S. thermophilus APC151 and L. Bulgaricus CH1 after $48 \mathrm{~h}$ of fermentation using $2.25 \mathrm{mg} / \mathrm{mL}$ glutamate at $42^{\circ} \mathrm{C}$. Meanwhile, Shan et al. [44] produced $231.23 \mathrm{mg} / 100 \mathrm{~g}$ of GABA in yogurt at a much shorter fermentation time of $5.75 \mathrm{~h}$ using commercial starter YC-X100 and L. plantarum NDC75017 at $36{ }^{\circ} \mathrm{C}$, but it required a high concentration of glutamate $(80 \mathrm{mM})$ and PLP $(18 \mu \mathrm{M})$. In contrast to the lengthy fermentation time and usage of PLP as reported in previous work, the current study succeeded in reducing the fermentation time to $7.25 \mathrm{~h}$ without the use of PLP.

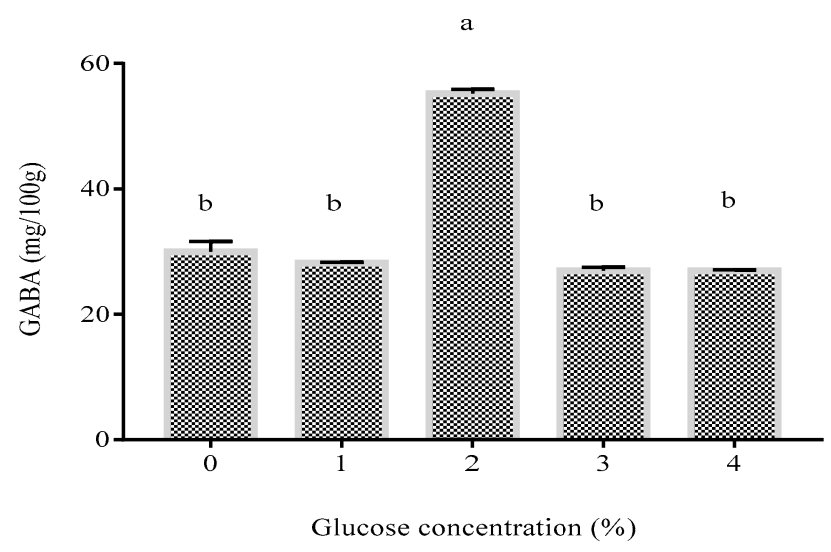

Figure 3. Effect of glucose induction at different concentrations on GABA content of yogurt. Different letters indicate a significant difference at $p<0.05$.

It is interesting to note that GABA production was not enhanced further when the glucose level increased to $3 \%$ and $4 \%$, possibly due to the imbalanced osmotic pressure as a result of a high glucose concentration, which interfered with the bacterial metabolism, inhibiting growth and thus lowering the GABA-producing ability $[45,46]$. A similar study also showed increased GABA content with the addition of $1 \%$ glucose in fermented soymilk after $24 \mathrm{~h} \mathrm{[47].} \mathrm{While} \mathrm{several} \mathrm{studies} \mathrm{have} \mathrm{reported} \mathrm{the}$ effect of glucose in fermentation medium, they focused on the enhancement of fatty acid production from Chlorella sp. and biomass accumulation from green algae Chlorella minutissima [48,49]. To date, the effect of glucose to enhance GABA production in yogurt fermentation has not been reported 
elsewhere. Glucose is regarded as the optimal fermentable sugar for utilization as a substrate by $\mathrm{LAB}[50,51]$. Therefore, the successful use of glucose to enhance GABA during LAB fermentation makes it an ideal choice to shorten the fermentation time, omit PLP, and allow minimal glutamate usage while favorably sustaining the growth of LAB without jeopardizing the product's sensorial properties.

\subsection{In Vivo Study: Blood Pressure-Lowering Efficacy in Rats}

As GABA is known to reduce blood pressure in experimental animal and human studies, an animal study was performed to evaluate the blood pressure-lowering efficacy of GABA-rich yogurt in spontaneously hypertensive rats (SHRs). Systolic blood pressure (SBP) was measured within $24 \mathrm{~h}$ following single oral administration of yogurts. A total of six samples were evaluated, namely GABA-rich yogurt at three different concentrations of 30,150, and $300 \mathrm{mg} / \mathrm{kg}$ (corresponding to $0.1,0.5$, and $1.0 \mathrm{mg} / \mathrm{kg}$ GABA, respectively), standard yogurt comprising only the starter culture (for yogurt-basis comparison), captopril $(50 \mathrm{mg} / \mathrm{kg}$, positive control), and distilled water (negative control). From Figure 4, the captopril group depicted the most prominent SBP-lowering effect, in line with its function as an antihypertensive agent while the distilled water group depicted no changes in SBP throughout the monitoring period. All three GABA dosages synchronously revealed the highest SBP reduction at $8 \mathrm{~h}$ post administration, recording values of $-65.22,-66.09$, and $-77.59 \mathrm{mmHg}$ for 0.1 , 0.5 , and $1.0 \mathrm{mg} / \mathrm{kg} \mathrm{GABA}$, respectively. It is also noted that the SBP in all GABA groups returned to baseline after $24 \mathrm{~h}$, indicating that GABA was fully degraded upon gastrointestinal digestion without a cumulative effect in the body.

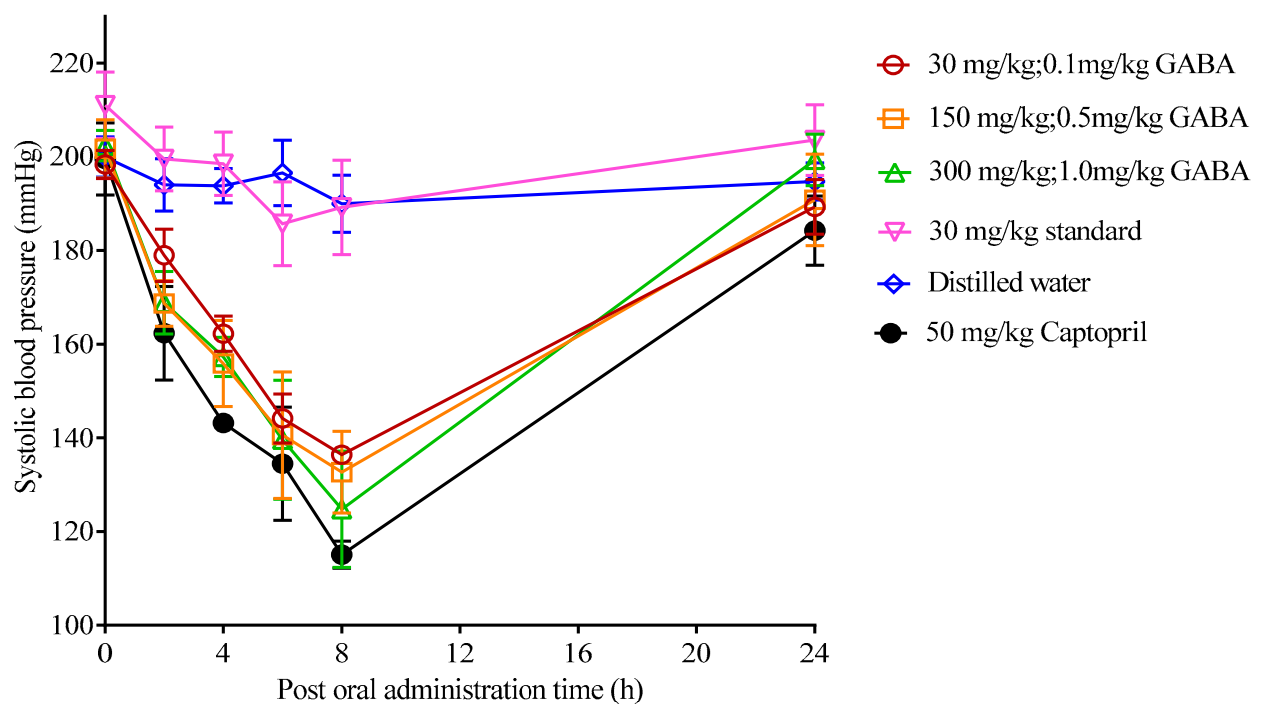

Figure 4. Mean systolic blood pressure of spontaneously hypertensive rats within $24 \mathrm{~h}$ of single oral administration of 30,150, and $300 \mathrm{mg} / \mathrm{kg}$ yogurt (consisting of $0.1,0.5$, and $1.0 \mathrm{mg} / \mathrm{kg} \mathrm{GABA}$, respectively) compared to $30 \mathrm{mg} / \mathrm{kg}$ standard yogurt, $50 \mathrm{mg} / \mathrm{kg}$ captopril, and distilled water.

From Table 3, the blood pressure-lowering efficacies between three GABA dosages depicted no significant differences $(p>0.05)$ at all measurement hours, establishing the effective GABA concentration at $0.1 \mathrm{mg} / \mathrm{kg}$ (equivalent to $30 \mathrm{mg} / \mathrm{kg}$ GABA-rich yogurt) to exert a blood pressure-lowering effect in SHR. This dosage is lower than that reported by Hayakawa et al. [5] and Yamakoshi et al. [52], who fed SHR with a single oral dosage of $0.05-5.00 \mathrm{mg} / \mathrm{kg}$ and $0.33-3.30 \mathrm{mg} / \mathrm{kg}$ GABA from fermented milk and soy sauce, respectively, to exert blood pressure-lowering activity. The blood pressure-lowering effect may be contributed by the reduction of oxidative stress in the rats. Previously, Kawakami et al. [53] reported the decrease in plasma 8-hydroxydeoxyguanosine and urinary isoprostane levels, two important compounds synthesized as a result of excessive oxidative stress [54], and act as markers for damaged 
oxidative cell membrane phospholipid [55], in SHRs fed with GABA-enriched brown rice. This indicated the positive correlation between consumption of GABA-rich food and reduction of oxidative stress.

Table 3. Difference in systolic blood pressure $(\mathrm{mmHg})$ in spontaneously hypertensive rats after single oral administration of yogurt.

\begin{tabular}{ccccccc}
\hline \multirow{2}{*}{$\begin{array}{c}\text { Time } \\
\text { (h) }\end{array}$} & \multirow{2}{*}{$\begin{array}{c}\text { Distilled } \\
\text { Water }\end{array}$} & Captopril & Standard & \multicolumn{2}{c}{ GABA Dosage (mg/kg) } \\
\cline { 5 - 7 } & & & Yogurt & $\mathbf{0 . 1}$ & $\mathbf{0 . 5}$ \\
\hline 2 & $5.46 \pm 8.69^{\mathrm{b}}$ & $37.22 \pm 10.00^{\mathrm{a}}$ & $21.60 \pm 6.58^{\mathrm{ab}}$ & $19.37 \pm 6.69^{\mathrm{ab}}$ & $30.76 \pm 14.17^{\mathrm{a}}$ & $33.50 \pm 14.76^{\mathrm{a}}$ \\
4 & $6.21 \pm 5.74^{\mathrm{d}}$ & $56.38 \pm 6.67^{\mathrm{a}}$ & $20.02 \pm 13.18^{\mathrm{cd}}$ & $36.10 \pm 5.89^{\mathrm{bc}}$ & $43.59 \pm 3.12^{\mathrm{ab}}$ & $45.07 \pm 11.19^{\mathrm{ab}}$ \\
6 & $3.68 \pm 2.76^{\mathrm{b}}$ & $69.81 \pm 10.82^{\mathrm{a}}$ & $26.79 \pm 8.88^{\mathrm{b}}$ & $60.35 \pm 7.46^{\mathrm{a}}$ & $9.28 \pm 17.99^{\mathrm{a}}$ & $62.77 \pm 16.87^{\mathrm{a}}$ \\
8 & $7.77 \pm 2.41^{\mathrm{c}}$ & $84.49 \pm 9.99^{\mathrm{a}}$ & $24.57 \pm 3.42^{\mathrm{c}}$ & $5.22 \pm 8.31^{\mathrm{b}}$ & $66.09 \pm 8.40^{\mathrm{b}}$ & $77.59 \pm 15.89^{\mathrm{ab}}$ \\
24 & $4.54 \pm 0.72^{\mathrm{a}}$ & $15.32 \pm 11.03^{\mathrm{a}}$ & $6.16 \pm 8.20^{\mathrm{a}}$ & $12.33 \pm 3.37^{\mathrm{a}}$ & $11.55 \pm 8.24^{\mathrm{a}}$ & $1.80 \pm 0.28^{\mathrm{a}}$ \\
\hline
\end{tabular}

The values are mean differences \pm standard deviations of systolic blood pressure $(\mathrm{mmHg})$ from baseline reading $(0 \mathrm{~h})$ of 30,150 , and $300 \mathrm{mg} / \mathrm{kg}$ yogurt (consisting $0.1,0.5$, and $1.0 \mathrm{mg} / \mathrm{kg}$ GABA, respectively) in comparison with $30 \mathrm{mg} / \mathrm{kg}$ standard yogurt, $50 \mathrm{mg} / \mathrm{kg}$ captopril, and distilled water. Different letters within the same row indicate significant differences $(p<0.05)$ among samples at the same monitoring hour.

Yogurt, as a protein-rich food, contains various peptides generated from bacterial metabolism, among which some may possess biological activity to exert blood pressure-lowering activity. Thus, standard yogurt was fed to SHR to evaluate the antihypertensive effect, if any, from the pool of peptide mixture generated during fermentation. The SBP readings in standard yogurt showed no significant difference from distilled water, indicating no antihypertensive activity in the yogurt sample. This observation confirms that the blood pressure-lowering activity in GABA-rich yogurt was due to the presence of GABA, irrespective of peptides, fostering the potential of GABA-rich yogurt as a functional dairy product that can be consumed regularly to promote blood pressure-lowering functionality.

\section{Conclusions}

Co-culturing starter culture with GABA-producing LAB strains (UPMC90 + UPMC91) successfully established a symbiotic relationship between these species that intensified GABA production in yogurt. Glucose induction at $2 \%(w / v)$ under optimized fermentation conditions delightfully produced a yogurt with increased GABA content and desirable product quality $(\mathrm{pH}$ and water-holding capacity). The lowered blood pressure in SHR upon single oral administration of GABA-rich yogurt signified its potential to be developed into a functional dairy product possessing a valuable antihypertensive property.

Author Contributions: Data curation, formal analysis, investigation, methodology, writing-original draft F.S.H.; writing - review and editing S.Y.C.; software, writing — review and editing M.Z.; supervision, resources A.S.M.H.; supervision, resources W.Z.W.I.; assisting investigation in animal study N.D.Z.; data curation H.W.; conceptualization, supervision, reviewing and editing, funding acquisition N.S. All authors have read and agreed to the published version of the manuscript.

Funding: This work was financially supported by Universiti Putra Malaysia under the PUTRA grant scheme (project number: GP-IPS/2016/9493300).

Conflicts of Interest: The authors declare no conflict of interest.

\section{References}

1. Rapsomaniki, E.; Timmis, A.; George, J.; Pujades-Rodriguez, M.; Shah, A.D.; Denaxas, S.; White, I.R.; Caulfield, M.J.; Deanfield, J.E.; Smeeth, L.; et al. Blood pressure and incidence of twelve cardiovascular diseases: Lifetime risks, healthy life-years lost, and age-specific associations in 1.25 million people. Lancet 2014, 383, 1899-1911. [CrossRef]

2. Vaes, B.; Beke, E.; Truyers, C.; Elli, S.; Buntinx, F.; Verbakel,J.Y.; Goderis, G.; Van Pottelbergh, G. The correlation between blood pressure and kidney function decline in older people: A registry-based cohort study. BMJ Open 2015, 5, 1-11. [CrossRef] [PubMed] 
3. World Health Organization Factsheet on Hypertension. Available online: https://www.who.int/news-room/ fact-sheets/detail/hypertension (accessed on 25 September 2020).

4. Yang, N.-C.; Jhou, K.-Y.; Tseng, C.Y. Antihypertensive effect of mulberry leaf aqueous extract containing $\gamma$-aminobutyric acid in spontaneously hypertensive rats. Food Chem. 2012, 132, 1796-1801. [CrossRef]

5. Hayakawa, K.; Kimura, M.; Kasaha, K.; Matsumoto, K.; Sansawa, H.; Yamori, Y. Effect of a $\gamma$-aminobutyric acid-enriched dairy product on the blood pressure of spontaneously hypertensive and normotensive Wistar-Kyoto rats. Br. J. Nutr. 2004, 92, 411-417. [CrossRef] [PubMed]

6. Linares, D.M.; O'Callaghan, T.F.; O'Connor, P.M.; Ross, R.P.; Stanton, C. Streptococcus thermophilus APC151 Strain Is Suitable for the Manufacture of Naturally GABA-Enriched Bioactive Yogurt. Front. Microbiol. 2016, 7, 1876. [CrossRef] [PubMed]

7. Coda, R.; Rizzello, C.G.; Gobbetti, M. Use of sourdough fermentation and pseudo-cereals and leguminous flours for the making of a functional bread enriched of $\gamma$-aminobutyric acid (GABA). Int. J. Food Microbiol. 2010, 137, 236-245. [CrossRef] [PubMed]

8. Pouliot-Mathieu, K.; Gardner-Fortier, C.; Lemieux, S.; St-Gelais, D.; Champagne, C.P.; Vuillemard, J.-C. Effect of cheese containing gamma-aminobutyric acid-producing lactic acid bacteria on blood pressure in men. PharmaNutrition 2013, 1, 141-148. [CrossRef]

9. Nejati, F.; Rizzello, C.G.; Di Cagno, R.; Sheikh-Zeinoddin, M.; Diviccaro, A.; Minervini, F.; Gobbetti, M. Manufacture of a functional fermented milk enriched of Angiotensin-I Converting Enzyme (ACE)-inhibitory peptides and $\gamma$-amino butyric acid (GABA). LWT Food Sci. Technol. 2013, 51, 183-189. [CrossRef]

10. Ratanaburee, A.; Kantachote, D.; Charernjiratrakul, W.; Sukhoom, A. Enhancement of gamma-aminobutyric acid (GABA) in Nham (Thai fermented pork sausage) using starter cultures of Lactobacillus namurensis NH2 and Pediococcus pentosaceus HN8. Int. J. Food Microbiol. 2013, 167, 170-176. [CrossRef]

11. Santos-Espinosa, A.; Beltrán-Barrientos, L.M.; Reyes-Díaz, R.; Mazorra-Manzano, M.; Ángel; Hernández-Mendoza, A.; González-Aguilar, G.A.; Sáyago-Ayerdi, S.G.; Vallejo-Cordoba, B.; González-Córdova, A.F. Gamma-aminobutyric acid (GABA) production in milk fermented by specific wild lactic acid bacteria strains isolated from artisanal Mexican cheeses. Ann. Microbiol. 2020, 70, 1-11. [CrossRef]

12. Hasegawa, M.; Yamane, D.; Funato, K.; Yoshida, A.; Sambongi, Y. Gamma-aminobutyric acid fermentation with date residue by a lactic acid bacterium, Lactobacillus brevis. J. Biosci. Bioeng. 2018, 125, 316-319. [CrossRef] [PubMed]

13. Watanabe, Y.; Hayakawa, K.; Ueno, H. Effects of co-culturing LAB on GABA production. J. Biol. Macromol. 2011, 11, 3-13.

14. Kim, J.A.; Park, M.S.; Kang, S.A.; Ji, G.E. Production of $\gamma$-aminobutyric acid during fermentation of Gastrodia elata Bl. by co-culture of Lactobacillus brevis GABA 100 with Bifidobacterium bifidum BGN4. Food Sci. Biotechnol. 2014, 23, 459-466. [CrossRef]

15. Tajabadi, N.; Ebrahimpour, A.; Baradaran, A.; Rahim, R.A.; Mahyudin, N.A.; Manap, Y.; Abu Bakar, F.; Saari, N. Optimization of $\gamma$-Aminobutyric Acid Production by Lactobacillus plantarum Taj-Apis362from Honeybees. Molecules 2015, 20, 6654-6669. [CrossRef]

16. Gaspar, P.; Carvalho, A.L.; Vinga, S.; Santos, H.; Neves, A.R. From physiology to systems metabolic engineering for the production of biochemicals by lactic acid bacteria. Biotechnol. Adv. 2013, 31, 764-788. [CrossRef]

17. Tajabadi, N.; Baradaran, A.; Ebrahimpour, A.; Rahim, R.A.; Abu Bakar, F.; Manap, M.Y.A.; Mohammed, A.S.; Saari, N. Overexpression and optimization of glutamate decarboxylase in Lactobacillus plantarum Taj-Apis 362 for high gamma-aminobutyric acid production. Microb. Biotechnol. 2015, 8, 623-632. [CrossRef]

18. Sandoval-Castilla, O.; Lobato-Calleros, C.; Aguirre-Mandujano, E.; Vernon-Carter, E. Microstructure and texture of yogurt as influenced by fat replacers. Int. Dairy J. 2004, 14, 151-159. [CrossRef]

19. Nguyen, H.T.H.; Ong, L.; Kentish, S.E.; Gras, S.L. The Effect of Fermentation Temperature on the Microstructure, Physicochemical and Rheological Properties of Probiotic Buffalo Yoghurt. Food Bioprocess Technol. 2014, 7, 2538-2548. [CrossRef]

20. Abdelmoneim, A.H.; Sherif, A.M.; Sameh, K.A. Rheological properties of yoghurt manufactured by using different types of hydrocolloids. Austin J. Nutr. Food Sci. 2016, 4, 1-6.

21. Vinderola, C.; Mocchiutti, P.; Reinheimer, J. Interactions Among Lactic Acid Starter and Probiotic Bacteria Used for Fermented Dairy Products. J. Dairy Sci. 2002, 85, 721-729. [CrossRef] 
22. Tamime, A.Y.; Robinson, R.K. Tamime and Robinson's Yoghurt: Science and Technology, 3rd ed.; Elsevier BV: Amsterdam, The Netherlands, 2007.

23. Feehily, C.; Karatzas, K.A. Role of glutamate metabolism in bacterial responses towards acid and other stresses. J. Appl. Microbiol. 2012, 114, 11-24. [CrossRef] [PubMed]

24. Kook, M.-C.; Cho, S.-C. Production of GABA (gamma amino butyric acid) by Lactic Acid Bacteria. Korean Food Sci. Anim. Resour. 2013, 33, 377-389. [CrossRef]

25. Xiao, T.; Yan, A.; Huang, J.; Jorgensen, E.M.; Shah, N.P. Comparative Peptidomic and Meta-transcriptomic Analyses Reveal Improved Gamma-amino butyric acid Production Machinery in Levilactobacillus brevis NPS-QW 145 Co-cultured with Streptococcus thermophilus ASCC1275 during Milk Fermentation. Appl. Environ. Microbiol. 2020. [CrossRef] [PubMed]

26. Hugenschmidt, S.; Schwenninger, S.M.; Lacroix, C. Concurrent high production of natural folate and vitamin B12 using a co-culture process with Lactobacillus plantarum SM39 and Propionibacterium freudenreichii DF13. Process. Biochem. 2011, 46, 1063-1070. [CrossRef]

27. Li, H.; Cao, Y. Lactic acid bacterial cell factories for gamma-aminobutyric acid. Amino Acids 2010, 39, 1107-1116. [CrossRef] [PubMed]

28. Lucey, J.A. Formation, Structural Properties, and Rheology of Acid-Coagulated Milk Gels, 4th ed.; Elsevier BV: Amsterdam, The Netherlands, 2017.

29. Lee, W.J.; Lucey, J.A. Formation and Physical Properties of Yogurt. Asian-Australas. J. Anim. Sci. 2010, 23, 1127-1136. [CrossRef]

30. Karthikeyan, R.S.; Rakshit, S.K.; Baradarajan, A. Optimization of batch fermentation conditions for dextran production. Bioprocess Eng. 1996, 15, 247-251. [CrossRef]

31. Whitcomb, P.J.; Anderson, M. RSM Simplified:Optimizing Processes Using Response Surface Methods for Design of Experiments; CRC Press: Boca Raton, FL, USA, 2004.

32. Li, H.; Qiu, T.; Gao, D.; Cao, Y. Medium optimization for production of gamma-aminobutyric acid by Lactobacillus brevis NCL912. Amino Acids 2010, 38, 1439-1445. [CrossRef]

33. Wardani, S.K.; Cahyanto, M.N.; Rahayu, E.S.; Utami, T. The effect of inoculum size and incubation temperature on cell growth, acid production and curd formation during milk fermentation by Lactobacillus plantarum Dad 13. Int. Food Res. J. 2017, 24, 921-926.

34. Gomaa, E.Z. Enhancement of $\gamma$-Amminobutyric Acid Production by Co-Culturing of Two Lactobacilli Strains. Asian J. Biotechnol. 2015, 7, 108-118. [CrossRef]

35. Sfakianakis, P.; Tzia, C. Conventional and Innovative Processing of Milk for Yogurt Manufacture; Development of Texture and Flavor: A Review. Foods 2014, 3, 176-193. [CrossRef] [PubMed]

36. Ab Kadir, S.; Wan-Mohtar, W.A.A.Q.I.; Mohammad, R.; Lim, S.A.H.; Mohammed, A.S.; Saari, N. Evaluation of commercial soy sauce koji strains of Aspergillus oryzae for $\gamma$-aminobutyric acid (GABA) production. J. Ind. Microbiol. Biotechnol. 2016, 43, 1387-1395. [CrossRef] [PubMed]

37. Kristo, E.; Biliaderis, C.; Tzanetakis, N. Modelling of the acidification process and rheological properties of milk fermented with a yogurt starter culture using response surface methodology. Food Chem. 2003, 83, 437-446. [CrossRef]

38. Lazaridou, A.; Serafeimidou, A.; Biliaderis, C.G.; Moschakis, T.; Tzanetakis, N. Structure development and acidification kinetics in fermented milk containing oat $\beta$-glucan, a yogurt culture and a probiotic strain. Food Hydrocoll. 2014, 39, 204-214. [CrossRef]

39. Bong, D.; Moraru, C.I. Use of micellar casein concentrate for Greek-style yogurt manufacturing: Effects on processing and product properties. J. Dairy Sci. 2014, 97, 1259-1269. [CrossRef]

40. Duttschaever, C.L.; Arnott, D.R.; Bullock, D.H. Quality Evaluation of Yogurt Produced Commercially in Ontario. J. Milk Food Technol. 1972, 35, 173-175. [CrossRef]

41. Akalın, A.; Unal, G.; Dinkci, N.; Hayaloglu, A. Microstructural, textural, and sensory characteristics of probiotic yogurts fortified with sodium calcium caseinate or whey protein concentrate. J. Dairy Sci. 2012, 95, 3617-3628. [CrossRef]

42. Li, H.; Qiu, T.; Huang, G.; Cao, Y. Production of gamma-aminobutyric acid by Lactobacillus brev is NCL912 using fed-batch fermentation. Microb. Cell Factories 2010, 9, 85. [CrossRef]

43. Chen, L.; Zhao, H.; Zhang, C.; Lu, Y.; Zhu, X.; Lu, Z. $\gamma$-Aminobutyric acid-rich yogurt fermented by Streptococcus salivarius subsp. thermophiles fmb5 apprars to have anti-diabetic effect on streptozotocin-induced diabetic mice. J. Funct. Foods 2016, 20, 267-275. [CrossRef] 
44. Shan, Y.; Man, C.; Han, X.; Li, L.; Guo, Y.; Deng, Y.; Li, T.; Zhang, L.; Jiang, Y. Evaluation of improved $\gamma$-aminobutyric acid production in yogurt using Lactobacillus plantarum NDC75017. J. Dairy Sci. 2015, 98, 2138-2149. [CrossRef]

45. Don, M.M.; Shoparwe, N.F. Kinetics of hyaluronic acid production by Streptococcus zooepidemicus considering the effect of glucose. Biochem. Eng. J. 2010, 49, 95-103. [CrossRef]

46. John, R.P.; Anisha, G.S.; Nampoothiri, K.M.; Pandey, A. Direct lactic acid fermentation: Focus on simultaneous saccharification and lactic acid production. Biotechnol. Adv. 2009, 27, 145-152. [CrossRef] [PubMed]

47. Xiao, T.; Shah, N.P. Lactic acid produced by Streptococcus thermophilus activated glutamate decarboxylase (GadA) in Lactobacillus brevis NPS-QW 145 to improve $\gamma$-amino butyric acid production during soymilk fermentation. LWT Food Sci. Technol. 2020, 110474. [CrossRef]

48. Feng, F.-Y.; Yang, W.; Jiang, G.-Z.; Xu, Y.; Kuang, T.-Y. Enhancement of fatty acid production of Chlorella sp. (Chlorophyceae) by addition of glucose and sodium thiosulphate to culture medium. Process. Biochem. 2005, 40, 1315-1318. [CrossRef]

49. Gautam, K.; Pareek, A.; Sharma, D.K. Biochemical composition of green alga Chlorella minutissima in mixotrophic cultures under the effect of different carbon sources. J. Biosci. Bioeng. 2013, 116, 624-627. [CrossRef] [PubMed]

50. Abdel-Rahman, M.A.; Tashiro, Y.; Sonomoto, K. Lactic acid production from lignocellulose-derived sugars using lactic acid bacteria: Overview and limits. J. Biotechnol. 2011, 156, 286-301. [CrossRef] [PubMed]

51. Xiong, T.; Li, X.; Guan, Q.; Peng, F.; Xie, M. Starter culture fermentation of Chinese sauerkraut: Growth, acidification and metabolic analyses. Food Control 2014, 41, 122-127. [CrossRef]

52. Yamakoshi, J.; Fukuda, S.; Satoh, T.; Tsuji, R.; Saito, M.; Obata, A.; Matsuyama, A.; Kikuchi, M.; Kawasaki, T. Antihypertensive and Natriuretic Effects of Less-Sodium Soy Sauce Containing $\gamma$-Aminobutyric Acid in Spontaneously Hypertensive Rats. Biosci. Biotechnol. Biochem. 2007, 71, 165-173. [CrossRef]

53. Kawakami, K.; Yamada, K.; Yamada, T.; Nabika, T.; Nomura, M. Antihypertensive Effect of $\gamma$-Aminobutyric Acid-Enriched Brown Rice on Spontaneously Hypertensive Rats. J. Nutr. Sci. Vitaminol. 2018, 64, 56-62. [CrossRef]

54. Shaughnessy, K.S.; Boswall, I.A.; Scanlan, A.P.; Gottschall-Pass, K.T.; Sweeney, M.I. Diets containing blueberry extract lower blood pressure in spontaneously hypertensive stroke-prone rats. Nutr. Res. 2009, 29, 130-138. [CrossRef]

55. Duarte, J.; Pérez-Palencia, R.; Vargas, F.; Ocete, M.A.; Pérez-Vizcaino, F.; Zarzuelo, A.; Tamargo, J. Antihypertensive effects of the flavonoid quercetin in spontaneously hypertensive rats. Br. J. Pharmacol. 2001, 133, 117-124. [CrossRef] [PubMed]

Publisher's Note: MDPI stays neutral with regard to jurisdictional claims in published maps and institutional affiliations.

(C) 2020 by the authors. Licensee MDPI, Basel, Switzerland. This article is an open access article distributed under the terms and conditions of the Creative Commons Attribution (CC BY) license (http://creativecommons.org/licenses/by/4.0/). 